\title{
Growth, carbohydrate assimilation and leaf gas exchange characteristics of Elaeis guineensis Jacq seedlings under nitrogen fertilization
}

\begin{abstract}
Aims: This study was conducted to characterise the growth, carbohydrate and leaf gas exchange patterns of oil palm seedlings performance (Deli Yangambi) under nitrogen fertilisation. Study Design: The palms were fertilised with three nitrogen rates: (1) Control (90 g/palm); (2) twice the control (180 g/palm), and (3) thrice the control (270 g/palm). Randomized complete block design (RCBD) with three replications was used during the experiment using Deli Yangambi seedlings Place and Duration of Study: Ladang 2, Universiti Putra Malaysia from March 2017 to June 2017. Methodology: The nitrogen treatments started when the oil palm seedlings reached four months old using Urea $(46 \% \mathrm{~N})$ as a source of nitrogen. Growth, carbohydrate and leaf gas exchange properties were measured at the end of the treatment period of two months. Results: As the level of nitrogen application increased, from $90-270 \mathrm{~g} / \mathrm{palm}$, the plant height, number of frond per plant, basal diameter, leaf area per seedling, root biomass, total dry matter, net assimilation rate (NAR) and relative growth rate (RGR) was statistically significantly increased between nitrogen treatments. The production of total non-structural carbohydrate (TNC) was reduced under high rates of nitrogen. The reduced in TNC under high nitrogen rates was supported by a decrease in sucrose and starch content under low nitrogen fertilisation. The net photosynthesis (A), stomatal conductance (gs), transpiration (E) and Intercellular CO2 also was found to be increased under high nitrogen rates indicated that higher rates of nitrogen would enhance the leaf gas exchange characteristics of the palms. Conclusion: In conclusion, the growth of oil palm seedlings growth was enhanced with high rates of nitrogen supplementation. As the nitrogen rates $(90>270 \mathrm{~g} / \mathrm{palm})$, more production of TNC was produced and increased the sink strength of the palms. The enhanced growth and TNC accumulation also increased the leaf gas exchange properties that were showed by increased in $\mathrm{A}, \mathrm{gs}, \mathrm{E}, \mathrm{Ci}$ and Water use efficiency in the oil palm seedlings.
\end{abstract}

Keyword: Deli Yangambi palms; Nitrogen uptake; Plant development; Carbohydrate; Leaf gas exchange 